\title{
Research on the problems and Countermeasures of innovation and entrepreneurship education of universities in Hebei Province
}

\author{
Chunyan Jiang ${ }^{a}$, Ping Guo ${ }^{b}$ and Xiulan Jiang ${ }^{c}$
}

School of economy and management, Shijiazhuang Tiedao University, Shijiazhuang 050043, China

ajiangchunyan0525@163.com, bguo-gp@sina.com, cjiangxiulan@stdu.edu.cn

\begin{abstract}
Under the background of the integration of Beijing, Tianjin and Hebei Province, the problem of employment difficulty of college graduates in Hebei province is increasing. To encourage innovation and entrepreneurship is the fundamental way to cultivate talents and solve the problem of employment. In Hebei Province, various forms of innovative entrepreneurship education, campus culture atmosphere to encourage innovation and entrepreneurship and preferential policies have been introduced. But entrepreneurship education appeared a lot of problems, such as utilitarian from innovation entrepreneurship competition and the lack of evaluation mechanism of business incubator, which inhibited the development of innovation and entrepreneurship education. Therefore, in order to promote innovation and entrepreneurship of college students, the college should reform the curriculum system of entrepreneurship education, introduce or develop the professional teachers and reform the evaluation mechanism to improve the existing mechanism.
\end{abstract}

Keywords: innovation and entrepreneurship of college students; entrepreneurship education; business incubator; innovation entrepreneurship competition.

\section{河北省高校创新创业教育发展现状、问题与对策研究}

\section{蒋春艳, 郭平, 蒋秀兰 \\ 石家庄铁道大学, 石家庄 中国}

摘 要: 京津冀一体化协同发展的大背景下, 河北省高校毕业生就业难问题加剧, 鼓励创新创 业是培养人才、解决就业难题的根本之路。河北省高校创新创业教育形式多样, 优惠政策不 断出台, 初步形成了鼓励创新创业的校园文化氛围, 但是创业教育流于形式、创新创业竞赛 功利化、创业卵孚化园区欠缺考评机制等问题突出，一定程度上抑制了创新创业教育的发展。 对此, 可以考虑通过改革创业教育课程体系、引进或培养专业师资和改革创新创业大赛考评 机制等办法来完善现行机制, 切实为大学生创新创业保驾护航。

关键词：大学生创新创业；创业教育；创业卵孚化器；大学生创业大赛.

\section{1. 前言}

京津冀一体化协同发展的大背景下, 就高校竞争力的整体排名而言, 河北省高校在一定程度 上落后于京津高校, 随着有关京津冀人才合理流动的相关政策的出台, 河北省调整产业结构 和产能过剩导致企业用工量减少, 人才市场中招聘的人才两极分化: 企业要么需要学历低工 资少的工人, 要么招聘高学历或丰富从业经验的高端人才, 高校大学生就业困难加剧, 鼓励 大学生创新创业是解决就业问题的根本之路, 因此, 发展完善创业教育体系、提升河北省高 校大学生创新创业的竞争力迫在眉睫。从前人研究成果来看, 黄兆信等人侧重分析与借鉴欧 美创业教育的发展经验和教训, 李伟铭等分析我国创业教育发展历史指出创业教育存在课程 设计不合理、师资圆乏、教学模式单一等问题, 但是很少有人分析京津冀一体化背景之下河 北省创新创业教育的发展和问题。本文拟对该问题展开研究, 为提高大学生创新创业教育质 量, 提高创业的成功率提供理论指导。 


\section{2. 河北省高校创新创业教育发展现状}

20 世纪末期, 国内高校开始了创新创业教育有益尝试, 继清华大学举办首届清华大学创业计 划大赛以来, 在国家有关部门和地方政府的扶持下, 其他高校陆续开展了创新创业教育的试 点, 涌现出了挑战杯大学生创业大赛、高校大学生创业教育或就业指导课、大学生创业孵化 园区等多种形式的创新创业教育形式, 一定程度上提高了大学生创新创业素质和能力。

2. 1. 河北省鼓励大学生创新创业的政策逐步完善

河北省陆续出台鼓励大学生创新创业的优惠政策, 涉及所得税减免、注册登记、设立创业孵 化器、将网络创业纳入小额贷款扶持范围, 享受社保补贴, 提高租金补贴等等, 切实便利了 大学生自主创业的顺利进行。

同时, 为扶持大学生自主创业的发展, 省内高校如河北大学、河北经贸大学、石家庄铁道大 学、河北农业大学等普遍建立的大学生自主创业园或者科技创业园区就是孵化器的一种典型 形式。作为典型的针对在校生的创业孵化器, 大学科技园强调大学与企业、社会的对接, 强 调高科技成果的转化和应用, 对经济、科技、教育和社会进步的作用已经日益显现, 一定程 度上提高了大学生自主创业的成功率。部分高校允许大学生在校期间休学自主创业, 一年后 重返校园继续学习, 提高了大学生创新创业的灵活性。

2.2. 省内大学生创新创业项目逐年增长

为解决大学生就业难问题, 近几年河北省政府加大对创新创业项目的扶持力度, 创新创业项 目数量逐年稳定增长。以石家庄铁道大学为例, 2014 年立项的省级创新创业项目为 30 项, 2015 年为 60 项, 增长较快。

2.3. 挑战杯创业大赛各高校踊跃参加和承办

随着挑战杯竞赛在全国展开, 越来越多大学生参与到创新创业大赛, 各参与高校也积极组织 专业教师为学生提供专业指导, 使得参赛院校组织学生参加此类大赛时功利心理较强。石家 庄铁道大学承办中电四挑战杯大学生科技作品大赛, 提高了学生的科研和创新能力。

2. 4. 创新创业校园文化氛围逐步形成

从省内大学生创业的发展路径来看, 早期大学生校内自主创业侧重解决自身的生活困难, 如 摆地推、上门推销商品, 创业层次较低, 科技含量不高, 很少结合本专业、本学科特色。而 那些没有自主创业的大学生对此类行为多数持旁观者的心态, 参与的积极性不高。随着挑战 杯、创新创业大赛等赛事的全面铺开, 在校大学生们会主动根据赛事要求, 组建创新创业团 队, 探讨创新创业项目, 主动联系校内外的创业指导教师。客观的说, 虽然挑战杯、创新创 业大赛还存在一定的缺陷或不足, 但是这些赛事的出现对于培养学生创新创业思维、提升高 校鼓励创新创业的文化氛围功不可没。绝大多数学生把参加此类比赛看作是大学阶段必经程 序，希望借这样的机会展示自我，创新创业的校园文化氛围初步形成。

2.5. 高校开设了创业教育课程

2012 年教育部下达《普通本科学校创业教育教学基本要求（试行）》的通知, 指出: 在普通 高等学校开展创业教育, 是建设创新型国家和人力资源强国的战略举措, 是落实以创业带动 就业、促进高校毕业生充分就业的重要措施。三年来, 多数高校已开设创业教育课程, 配备 了专业的师资, 甚至开设了专业的创业教育教研室。

\section{3. 河北省高校创新创业教育存在的问题}

3. 1. 创新创业大赛披上功利外衣

虽然创新创业项目数量逐年稳定增长, 学生创业的积极性很高, 但是因为缺乏专业师资和后 期帮扶, 项目要求期限短, 多以 1 年为主, 导致多数项目虽然结项, 但最终都流于形式, 学 生或者提交创业报告, 或者象征性的拿出产品或者在教师的大力扶持下发表论文（此类项目 在某些高校已成为职称评定的条件之一），后期根本没有市场化运作，更谈不上后续创业发 
展。挑战杯虽然发展较早, 项目数量较多, 但多数局限于创业计划书, 对于学生后期是否真 正以此计划书来开展创业无有效的监督机制。

3.2. 高校创业教育课程流于形式

创业教育旨在培养学生的创业意识、创业思维、创业技能等综合素质, 使其最终具有一定的 创业能力。但是, 各高校创业教育课程建设上出现了下列问题: (1) 创业教育本属于通识教 育的范畴, 可以应用于诸多学科领域, 因此适宜面向全体学生, 融入专业人才培养的全过程。 但是从省内高校来看, 创业教育课程多被设置为面向部分学生的选修课, 课时较短短, 一学 期 32 个或 48 个课时, 学分有限。（2）授课形式以传统的课堂灌输为主, 学生缺少接触社会 实践锻炼的机会，没有来自企业和社会的实践导师。（3）授课师资以经济、管理专业课教师 为主, 没有系统的创业理论学习和实践经验积累, 具体创业环节上很难为学生提供后续指导。 这些问题导致修习此课程的学生出现了严重的两极分化: 一部分学生确实想创业, 通过课程 学到了创业基本素质和基础知识, 但是校方不能提供足够的时间让这些学生一展所长, 因为 他们需要修满专业学分, 而创业需要全身心的投入, 多数高校没有建立创业能够抵补其他专 业课程学分的机制, 学生处于两难境地, 既然熊掌与鱼翅不可兼得, 只能以学业为重; 另一 部分学生修习此课程纯粹是为了拿学分, 上课的动力本就不足, 加之课程考核多以论文或创 业计划书为主, 比较容易拿到学分。

\section{3. 创业孵化园区发展欠缺绩效考评机制}

河北省各高校相继设立了创业孵化园区, 出台了创业孵化园的管理制度和考核方法, 但是省 内各高校的孵化器建设大多刚刚起步, 顺应政策形势设立, 行政色彩浓厚, 缺乏有效的创业 孵化绩效考评机制, 导致创业孵化器功能单一、定位不明确、缺乏长期发展战略、在孵创业 项目雷同、出孵项目市场认可度不高、创业导师队伍建设滞后及低水平的重复建设等问题严 重, 在很大程度上影响了大学生自主创业的绩效。

\section{4. 完善和发展高校创新创业教育的对策}

4. 1. 改革创新创业教育课程体系

中国经济新常态的内涵之一是实现经济发展方式由要素驱动、投资驱动转向创新驱动, 在校 大学生应成为未来创新立国的主体, 作为教育资源的提供者一高校也应更新观念, 改革课程 体系, 从现在的仅面向部分学生的创业教育选修课, 转向设立创新创业的必修课, 拓宽学生 的创新思维, 切实为社会培养创新创业型人才。对此, 上海理工大学进行了有益的尝试, 为 河北省高校开设创新创业必修课程提供了参考。（1）科学合理设置学分和学时: 参照上海理 工大学的做法, 从大一开始设立创新创业必修课, 覆盖全体学生, 课程学分 4-6 分, 历时四 年，采取理论+实践的形式，由专业师资对创业团队提供一对一指导；（2）改革授课形式， 由专业教师传统课堂讲授转向沙盘模拟和实战演练, 学生团队协作从项目立项、运作和产品 上市及后续发展全过程自行设计, 由专业教师模拟实践场景, 提出问题, 交由团队成员去解 决; (3) 改革课程考核方式, 与授课形式改革对接, 实现全过程考核, 突出实践考核部分的 权重, 降低笔试部分的比重; (4) 积极联系校内外实习机会, 为学生创新创业基本素质教育 提供真实体验。从大学生创业项目类型来看, 理工科学生偏向新型的机器设备或专利、专有 技术的研发和推广, 为学生开放专业的理工类实验室对于此类项目研究的开展非常关键。而 经管类学生的自主创业项目更偏向与大学生的衣食住行直接相关, 对于这类项目, 高校的后 勤主管部门应该能够为学生提供足够的实践空间, 可以尝试在后勤服务领域比如餐厅、校内 超市等引入学生管理团队和服务团队, 学生处应能为大学校园内部交易系统的建立搭建网络 平台。

\section{2. 引进或培养创新创业师资}

师资队伍的建设对成功的创业教育至关重要。针对省内高校创业教育师资力量不足，建议 (1) 加强对师资的培训力度, 推荐中青年骨干教师到创业氛围较好的江浙高校去进修, 提高师资 授课水平。（2）鼓励高校教师积极参加创新创业研讨会，与其他院校交流，不断学习新的创 
业理论, 完善教学体系和内容。（3）推广创新创业客座教授制度, 高校学生处积极招聘创业 成功人士或校友作为客座教授, 定期开展创业讲座, 分享创业的经验, 解决大学生创业中的 问题和困惑。

4. 3. 改革创新创业大赛考评机制

针对目前创新创业大赛考评环节存在的问题, 相关主管部门在下发创新创业项目时, 可以考 虑：（1）适当延长项目考评期间，从 1 年增加至 3 年或 4 年，严格按照项目实施计划，分期 拨付项目经费, 如果某年度实施计划未完成, 下年度经费停止拨付。（2）改革项目考评方式, 逐步取消传统商业计划书成果方式, 逐渐增加实际操作项目考评的比重, 切实在结项时让学 生能拿出新设计、新产品、新专利等。（3）建立创新创业项目追踪机制, 每一个成功立项的 创新创业项目都设立一个永久联系人, 比如指导教师, 即使项目结束, 永久联系人也要连续 3-5 年持续反馈项目的后续发展情况。如果后续发展情况较好, 项目建设取得了良好的经济 和社会效益，由主管部门设立奖励基金进行奖励。

4. 4. 构建大学创业孵化园绩效评价机制

针对高校在创业孵化园绩效考评机制上的欠缺, 可以参考社会企业举办的大型孵化器的评价 指标体系, 在绩效评价上突出公益属性, 而非盈利属性。具体来说, 各高校可结合自身特色, 从服务能力、孵化绩效和增长潜能三个方面来构建评价指标体系, 自行设定三个维度的权重, 具体评价指标可以设置理想值, 通过对比实际值与理想值的差距, 找出孵化器建设的不足, 纠正不合理的管理和服务制度, 提高孵化绩效。

\section{5. 结论}

本文在分析河北省创新创业教育发展现状的基础上, 结合发达地区的做法, 指出河北省创新 创业教育存在的不足, 并提出从构建大学创业孵化园绩效评价机制、改革创新创业大赛考评 机制、加强师资培训和改革创新创业课程体系等方面来完善现行制度, 对提高大学生创业质 量、解决就业问题有重大指导意义。

\section{致谢}

本文是河北省科技计划项目《大学生校内自主创业校园环境优化研究》成果, 编号 144576103D.

\section{References}

[1].Zhaoxin Huang, et al. On the Integration between entrepreneur education and professional education. Educational Research. Vol.407 (2013) No. 12, p. 59-67.

[2].Weiming Li ,et al. Research on Ten-year entrepreneurship education in Chinese universities: Evolution, problem and system construction. Educational Research Vol.401 (2013) No. 6, p. 42-51.

[3]. Zhaoxin Huang, et al.Collaboration of entrepreneurship education in America: concept, model and lessons. Journal of Higher Education. Vol.31 (2010) No. 4, p.105-109 